\title{
O papel do docente na educação à distância: perspectivas para o novo
}

\section{profissional}

\author{
The teacher's role in distance learning: perspectives for the new professional
}

Willian Toneli da Silva 1; Eunice do Nascimento Silva 2

\author{
1 E-mail: \\ wtoneli@yahoo.com.br;
}

FUNORTE

2 E-mail:

Eunice1609@gmail.com

FUNORTE

\section{Resumo}

Com a expansão do mundo globalizado e a criação e ampliação dos recursos tecnológicos e de sistemas de informação, cada vez mais disponíveis e eficientes, surgem outras necessidades e particularidades demandadas pelo público em geral, visando sempre o crescimento pessoal e profissional. Nesta perspectiva, objetivouse investigar quais os papéis e requisitos básicos do docente na Educação à Distância. Para tanto, necessitou de um aprofundamento teórico, visando um entendimento das questões de tecnologia e sistemas da informação e a história da Educação à Distância ao longo dos tempos. A Educação à Distância surge dentro de uma discussão e reflexão dos caminhos que a educação seguirá nos próximos anos, pois as fontes de conectividade ganham corpo a cada dia, nos remetendo a uma sociedade globalizada, mundializada, conectada e on-line 24 horas por dia. Analisamos o papel do docente neste processo e percebemos que o professor deixa de ter um papel de somente repassar as informações e passa a ser um agente de transformação, de impulsionamento das ações de transformação, que orienta os seus alunos para que esses possam agir com autonomia, disciplina, organização e foco nos seus objetivos. Desta forma, pode-se concluir que o fato de a Educação à Distância estar crescendo não há comprovação de que esse segmento de ensino irá superar a educação presencial, tida como convencional, até o momento. Pelas percepções do estudo em questão, respaldados pelos autores que contribuíram com essa discussão, podemos perceber uma tendência enorme de crescimento dessa modalidade de ensino e uma área próspera e faminta de profissionais qualificados, gabaritados e que atendam aos requisitos para o exercício dessa nova função dentro da educação. As novas tecnologias irão direcionar essa modalidade de ensino para trazem facilidade e comodidade aos alunos e acadêmicos e outras responsabilidades, desafios, objetivos e metas aos docentes.

PALAVRAS-CHAVE: Educação à Distância, Docente, Ambiente Virtual de Aprendizagem

\begin{abstract}
With the expansion of the globalized world and the creation and expansion of technological resources and information systems, increasingly available and efficient, there are other needs and characteristics demanded by the general public, always seeking personal and professional growth. In this perspective, the objective was to investigate what roles and the basic teaching requirements in Distance Education. For this, we needed a theoretical study, seeking an understanding of technology issues and systems of information and history Education Distance over time. Distance education comes within a discussion and reflection of the ways that education will follow in the coming years, as the connectivity sources take shape every day, in referring to a globalized society, globalized, connected and online 24 bours a day. We analyze the role of the teacher in this process and we realize that the teacher no longer has a role to only pass on the information and becomes an agent processing, boosting the shares of transformation, which orients its students so that they can act with autonomy, discipline, organization and focus on your goals. Thus, it can be concluded that the fact that distance education is growing there is no evidence that this educational segment will surpass the classroom education, considered conventional, so far. The perceptions of the present study, backed by the authors who contributed to this discussion, we can see a huge growth trend this type of education and a prosperous and hungry field of qualified professionals, guideposts and that meet the requirements for the exercise of this new function within education. New technologies will drive this type of education to bring ease and convenience to students and academics and other responsibilities, challenges, goals and objectives for teachers.
\end{abstract}

Keywords: Distance Education, Teacher, Virtual Learning Environment. 


\section{Introdução}

Com a expansão do mundo globalizado e a criação e ampliação dos recursos tecnológicos e de sistemas de informação, cada vez mais disponíveis e eficientes, surgem outras necessidades e particularidades demandadas pelo público em geral, visando sempre o crescimento pessoal e profissional.

A Educação à Distância surge dentro de uma discussão e reflexão dos caminhos que a educação seguirá nos próximos anos, pois as fontes de conectividade ganham corpo a cada dia, nos remetendo a uma sociedade globalizada, mundializada, conectada e on-line 24 horas por dia.

Segundo VIDAL (2010, p.12),

A educação a distância apresenta características específicas, rompendo com a concepção da presencialidade no processo de ensino-aprendizagem. Para a EAD, o ato pedagógico não é mais centrado na figura do professor, e não parte mais do pressuposto de que a aprendizagem só acontece a partir de uma aula realizada com a presença deste e do aluno.

Em sua obra, NOVA (2003, p.5) comenta sobre a abrangência da Educação à Distância, suas dificuldades e particularidades.

Desde cursos informais de culinária, tai chi chu an ou eletrônica básica, até cursos de graduação e pós-graduação, nas diversas áreas do conhecimento. Vemos também o desenvolvimento acelerado de softwares e tecnologias de rede criada ou adaptada para servir a esse mercado em expansão. Pouco a pouco, percebe-se que as políticas públicas educacionais, em praticamente todos os países ocidentais, já começam a definir posicionamentos mais claros e detalhados sobre o assunto, incentivando muitas vezes o surgimento de programas de Educação à Distância (EAD) de portes nacionais, assim como introduzindo limites e regras para os mesmos. Do ponto de vista acadêmico, o volume de produção de artigos, ensaios, livros, dissertações e teses também tem crescido significativamente. O interesse social pode ser percebido pelo volume de discussões na mídia em geral.

Pensando nisto, podemos perceber o crescimento, não somente no Brasil como no mundo todo, da Educação à Distância - EAD, que de acordo com RASLAN (2009. p.25), a sua origem está relacionada às necessidades de preparo profissional e cultural e configura-se 


\begin{abstract}
E3, Revista de Economia, Empresas e Empreendedores como uma nova possibilidade àqueles que, por vários motivos, não prąerh P frewum estabelecimento de ensino presencial.
\end{abstract}

VEIGA (2004. p, 15) no decorrer de sua obra conceitua ensino como sendo um ato interpessoal, intencional e flexível conectado a seu contexto social mais amplo. O ensino não existe por si mesmo, mas na relação com a pesquisa, a aprendizagem e a avaliação.

Diante de todo o crescimento da Educação à Distância, seja pelo desejo de qualificação profissional e pessoal, ou seja, pelos critérios de tempo e frequência mínima que são exigidos a Educação Presencial, surge uma tendência de os alunos recorrem a essa modalidade de ensino, visando angariar conhecimentos e informações a respeito daquele curso que se faz necessária a sua formação.

Tendo em vista a capacitação desse aluno, através de uma modalidade de ensino à distância, se faz necessário também, capacitar esse professor para o exercício desta nova função. $O$ objetivo principal desse artigo é o de analisar se há uma qualificação específica para que esse professor possa exercer esse trabalho e de verificar como esse profissional se qualifica (presencial ou à distância), quais são os requisitos básicos necessários para o exercício dessa docência.

Como se dá também o fato de separarmos fisicamente os professores dos alunos, ação de distinção básica da Educação à Distância da Educação Presencial. Esse aluno deve ter uma capacidade de síntese, disciplina estudantil, capacidade de absorver conhecimento através de material impresso e por meios digitais, sem a efetiva presença do professor para auxiliá-lo.

\title{
Educação à Distância: Histórico e evolução
}

Para que possamos entender melhor essa modalidade de ensino, precisamos ordenar o seu crescente desenvolvimento ao longo do tempo no Brasil, seu princípio, a sua construção histórica e a sua evolução.

No início do século XX surgem algumas experiências ligadas a Educação à Distância no Brasil. Utilizava-se de recursos impressos e rádio para a sua difusão e disseminação entre a sociedade. De acordo com VIDAL (2010, p.14),

A Rádio Sociedade do Rio de Janeiro, criada em 1923, mais tarde incorporada pelo Ministério da Educação, é uma das primeiras iniciativas de EAD que se tem notícia. O Instituto Monitor criado em 1939 e o Instituto Universal Brasileiro fundado em 1941 são exemplos de iniciativas que ainda hoje ofertam cursos por correspondência atendendo estudantes em todo o território nacional. 


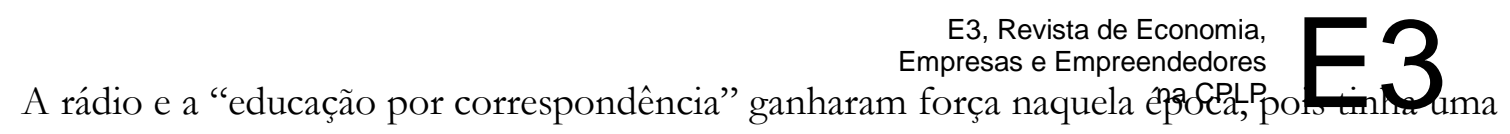
particularidade e especificidade que traziam àquela modalidade de ensino a possibilidade de angariar conhecimentos de uma maneira distinta. Traziam sim uma carga de aprendizado individual e com um grau de dedicação e disciplina muito grande, porém começava a se incorporar às novas rotinas dos estudantes e trabalhadores ansiosos por informação e conhecimento.

Já na década de 1960, segundo GOMES (2011, p.7),

O governo militar criou o Centro Brasileiro de TV Educativa, que produziu centenas de programas educativos à distância. A televisão foi um marco da EAD nos anos 80 no Brasil, especialmente com os telecursos de primeiro e segundo graus, que foram transmitidos em mais de 40 emissoras.

As fontes de comunicação e de disseminação desse novo modelo de educação ganham outras formas e angariam novos adeptos, seja pela falta de tempo para realização de cursos presenciais, sejam pela vontade e interesse de conhecer algo novo, com formatos diferentes, com um nível de praticidade desejado pelos alunos daquela época.

VIDAL (2010, p.15), destaca ainda que,

A partir dos anos 1990 a educação à distância começa a ser concebida num contexto mais amplo dos Projetos Pedagógicos Nacionais ganhando mais espaço no cenário educacional, sendo os primeiros grandes projetos relacionados com a televisão.

Já em 1996, a Educação à Distância é inserida na nas diretrizes e bases da educação nacional, através da Lei N 9.394, DE 20 DE DEZEMBRO DE 1996 - Art. 80. A referida Lei trata do incentivo, desenvolvimento e veiculação de programas de ensino à distância, em todos os níveis e modalidades de ensino e de educação continuada.

VIDAL (2010, p.15), ainda contribui e destaca que:

Antes mesmo da publicação da LDB em 1996, a Universidade Federal de Mato Grosso (UFMT) em 1994 realizou o primeiro processo seletivo para um curso de graduação à distância, dirigido para formação de professores das séries iniciais do Ensino Fundamental. O referido curso foi oferecido em algumas cidades do Estado, contando com 352 alunos matriculados. O curso da UFMT utilizava material impresso com mediação de tutoria presencial nas cidades polos das turmas. Este modelo passou a servir de referência para outras instituições de ensino superior que, aos poucos foram iniciando suas atividades na área de EAD. 
Contribui também para esse processo de formatação e fortalecimento da Educação à

Distância a UAB - Universidade Aberta do Brasil, que segundo o site da CAPES, "trata-se de um sistema integrado por universidades públicas que oferece cursos de nível superior para camadas da população que têm dificuldade de acesso à formação universitária, por meio do uso da metodologia da educação à distância".

O Sistema UAB - Universidade Aberta do Brasil, foi instituído pelo Decreto 5.800, de 8 de junho de 2006, visando desenvolver e expandir a oferta de cursos e programas de educação superior no País.

Várias formas de comunicação virtual começam a ser inseridas neste contexto. TV por satélite, videoconferências, vídeo-aulas, difusão do sistema de telefonia, expansão e massificação da internet e telefonia móvel são algum dos meios disponíveis pra fomentar e impulsionar esse novo modelo educacional.

\section{Transformação do cenário educacional desconhecido: revolução digital}

A partir desse momento histórico, a Educação à Distância começa a ser percebida como um modelo educacional específico. As aberturas dos mercados, aliados ao advento da globalização, trazem consigo a expansão das tecnologias voltadas para a difusão e ampliação da internet e a crescente diversificação de hardwares e softwares que auxiliam diretamente todo esse processo de ampliação de ofertas de cursos e programas de capacitação.

NOVA (2003, p.8) comenta que:

A proliferação das redes de comunicação digital trazem inúmeras possibilidades e perspectivas para o universo educacional. Tecnicamente, esse processo, que vem sendo chamado de Revolução Digital, diz respeito à criação de grandes sistemas de rede de comunicação integradas, com suportes de armazenamento e transmissão de dados digitais (códigos binários, traduzíveis sob diversas interfaces). E isso, que pode a primeira vista parecer algo insignificante, é base para transformações de portes ainda incalculáveis para a economia, a política, a cultura, a medicina, o lazer, a ciência, a educação.

O conjunto de informações, conhecimentos e habilidades passam a ser virtualizados, ou seja, disseminados através de sistemas e ambientes virtuais de aprendizagem - AVA. O acesso a esse conjunto de ferramentas pode ser feito remotamente, a qualquer horário, de qualquer local e a qualquer tempo, bastando apenas estar conectado a rede mundial e virtual de comunicação - a internet. Todo conteúdo (livros, apostilas, plano de curso, plano de ensino, 
exercícios e avaliações) ficam armazenados e são acessados pelos alunßs $\begin{array}{r}\text { E3, Revista de Economia, } \\ \text { Empresas e Empreendedores }\end{array}$ ou seja, sem a necessidade de presença física desse aluno.

NOVA (2003, p.14 e 15) complementa em sua obra as questões ligadas a disposição das informações de forma virtual.

O fato das informações (discursos) estarem dispostas em redes digitais acaba elevando o grau de possibilidade de metamorfose constante dos produtos e saberes, dificultando, assim, a cristalização de ideias, conceitos e estéticas. Isso implica na ampliação do caráter coletivo do saber, fruto da viabilidade da troca dinâmica e instantânea de saberes singulares de um grande número de agentes produtivos. Por sua vez, a possibilidade de que muitos sejam ao mesmo tempo produtores, difusores e consumidores de discursos viabiliza as condições para a concretização de uma situação na qual não existiriam mais centros exclusivos de produção, descaracterizando (ao menos parcialmente), assim, o chamado "consumo de massa". Nesse sentido, o próprio saber poderia se transformar num grande hipertexto, construído e reconstruído, a milhares de mãos e cérebros, sem eixos centrais.

Levamos em consideração que esse conjunto de atributos que devem ser desenvolvidos e melhorados pelos alunos na Educação à Distância, podem ser alcançados através da discussão e desenvolvimento das competências desses alunos. TEPERINO (2006. p, 66) contribui afirmando que:

É importante considerar que o processo de educação, focado no desenvolvimento de competências, é centrado na aprendizagem dos participantes, para sua atuação como pessoa, como profissional e como cidadão. A aprendizagem tem sido tradicionalmente entendida como o processo psicológico pelo qual o indivíduo adquire as competências para o trabalho, ou seja, desenvolve conhecimentos, habilidades e atitudes. Já a competência refere-se à capacidade de realizar algo. Para isso, é necessário possuir recursos e utilizá-los em determinada situação, com o objetivo de obter resultados.

Dentro dos ambientes virtuais de aprendizagem podemos encontrar e destacar diversas ferramentas que auxiliam na interação entre alunos e professores. As videoconferências, chats, aulas virtuais gravadas (vídeo aulas), wikis, e-mail, fóruns de discussão, etc. Essas ferramentas entre outras, auxiliam a agregar valor na capacitação dos alunos, visando com que estes estejam aptos e se adaptem facilmente à essa nova modalidade de ensino. 
E3, Revista de Economia,
Empresas e Empreendedores acontecer de várias maneiras envolvendo recursos tecnológicos e meios de comunicações variados".

A revolução digital é algo que necessita de um estudo e de uma discussão mais ampla e profunda. Não podemos, porém, deixar de entender e aceitar essas mudanças tecnológicas e de sistemas de informações, pois a sua propagação diante dos fenômenos da globalização, da mundialização da informação e da internet, passam a ser tratados com um caminho de mão única, somente de ida e sem volta.

\section{O papel do docente no processo de Educação à Distância}

Como pudemos perceber a utilização desse novo modelo de aprendizagem e disseminação de conhecimento, apesar de ser utilizado a mais de um século, é ainda recente em termos das novas tecnologias disponíveis hoje no mercado. Ainda não sabemos muito bem quais são os papéis de cada um e principalmente quais são os requisitos básicos para que professores possam exercer as suas atividades de docência, sem que ocorra a perda da qualidade da educação nessa modalidade de ensino seja ela à distância ou semi presencial.

Quando falamos em papéis e requisitos básicos necessários para que esse educador possa exercer o trabalho da docência, devemos levar em consideração todo o conjunto de informações, conhecimentos, habilidades, formação profissional e pessoal, capacidade de interação e de liderança, empatia, controle, coordenação, interatividade, criatividade, foco, entre outros, que esse docente deverá ter para suprir a sua presença física, que deixa a sala de aula e acessa o ambiente virtual de aprendizagem.

Devemos e precisamos buscar o professor ideal. TARDIF (2002. p, 39), contribui descrevendo a forma como pensa ser esse professor ideal:

... é alguém que deve conhecer sua matéria, sua disciplina e seu programa, além de possuir certos conhecimentos relativos às ciências da educação e à pedagogia e desenvolver uma saber prático baseado em sua experiência cotidiana com os alunos.

NOVA (2003, p.18) presta mais uma contribuição comentando que:

É preciso superar-se a postura ainda existente do professor transmissor de conhecimentos. Passando, sim, a ser aquele que imprime a direção que leva à apropriação do conhecimento que se dá na interação. Interação entre aluno/professor e aluno/aluno, valorizando-se o trabalho de parceria cognitiva, elaborando-se situações pedagógicas onde as diversas linguagens estejam presentes. As linguagens são, na verdade, o instrumento fundamental de 


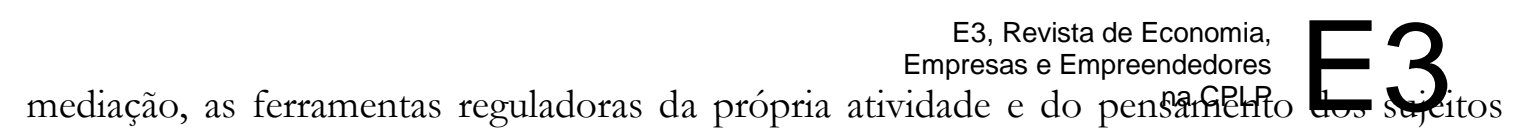

envolvidos. É preciso buscar o desenvolvimento de um espírito pesquisador e criativo entre os docentes, para que não sejam reprodutores, incapazes de refletir e modificar sua prática profissional, este processo criativo é sempre coletivo, na medida em que a memória e a experiência humana são patrimônio social.

O professor deixa de ter um papel de somente repassar as informações e passa a ser um agente de transformação, impulsionando as ações, que orientam os seus alunos para que esses possam agir com autonomia, disciplina, organização e foco nos seus objetivos.

ESTEVE (2004, p. 160) afirma que "a ação educacional está nas mãos de nossos professores, e, portanto, a qualidade da educação sempre dependerá da qualidade do pessoal que nela trabalha".

NOVA (2003, p.18-19) ainda complementa e destaca mais uma vez a importância do professor neste processo de ensino aprendizagem, onde os processos de comunicação são mais importantes que os processos de informação.

Sua importância, em vez de ser minimizada, seria potencializada e sua responsabilidade social aumentada. Seu lugar de saber seria o do saber humano e não o do saber informações, sendo a comunicação mais importante do que a informação. Sua função não mais seria a de passar conteúdos dos quais "só ele possuiria", mas a de orientar o processo de construção do conhecimento pelo aluno, apontando-lhe a necessidade de uma atitude crítica e ativa em relação ao mundo de informações a que é submetido diariamente. Caberia ao professor fazer o aluno compreender que, com as informações recebidas, ele pode construir conhecimento e fazer ciência e/ou arte, mostrando-lhe alguns possíveis caminhos para isso, possibilitandoo a recombinação e ressignificação contínua de saberes, fantasias, desejos e lembranças, numa prática pedagógica que viabilizaria a concretização daquilo que a comunidade necessita e deseja.

Também precisamos levar em conta a formação que esse professor teve ou terá de exercer perante o processo da docência. Como se dá essa formação? Ocorre de forma presencial, semipresencial ou à distância? Quais são esses saberes docentes?

CANDAU (1994. p, 37) descreve a sua forma de pensar sobre os saberes docentes necessários ao exercício da profissão, dizendo que:

Assumir a perspectiva de que a docência se estrutura sobre saberes próprios, intrínsecos à sua natureza e objetivos, é reconhecer uma condição profissional para a atividade do 
E3, Revista de Economia,
Empresas e Empreendedores identificar a natureza desses saberes e em que medida àqueles ligados à didática são fundamentais para estruturação profissional do professor, devendo constituir o constructo de sua formação inicial e/ou continuada.

DINIZ (2011, p. 89) demonstra em linhas gerais, de que forma isso acontece e dá algumas sugestões sobre as melhores maneiras de se realizar a preparação básica para essa nova modalidade de ensino.

Em praticamente 100\% dos casos, hoje em dia, um professor terá desenvolvido toda sua formação básica e profissional de forma exclusivamente presencial. Como consequência, temos muita experiência e vivência com ensino presencial, mas praticamente nenhuma experiência própria com educação a distância e educação on-line. Somente essa constatação já deveria ser suficiente para nos fazer procurar desenvolver uma preparação específica para educação on-line. Mas, além de nossa total inexperiência, o próprio ambiente on-line apresenta diferenças significativas com relação ao ambiente exclusivamente presencial. Essas diferenças precisam ser conhecidas e experimentadas por aqueles que atuarão como docentes em cursos on-line. A melhor maneira de realizar essa preparação é fazê-la acontecer por meio de um curso on-line que reproduza com a máxima fidelidade o tipo de situação e de experiência que os futuros alunos terão. Quando possível, a realização de cursos semipresenciais também pode ser considerada. Mas será absoluto contrassenso tentar desenvolver esse tipo de preparação através de cursos exclusivamente presenciais.

DINIZ (2011, p. 89) ainda nos traz de forma clara e objetiva a sua percepção quanto ao preparo desse docente para exercício da Educação à Distância:

$\mathrm{Na}$ preparação do professor não se deve considerar apenas e tão somente questões relacionadas com a operação de sistemas e de programas para educação on-line. A principal preparação deverá ser didático pedagógica, especialmente relativas a metodologias e estratégias de ensino on-line. Numa situação ideal, um professor, antes de assumir uma turma on-line e logo depois de passar por um processo on-line de capacitação pedagógica específica, deveria poder observar um professor mais experiente em ambiente on-line, acompanhando um curso on-line numa situação real. E, em sua primeira experiência como docente on-line deve poder contar com um bom suporte e acompanhamento pedagógico, talvez deum professor mais experiente. A qualquer custo deve-se evitar colocar um professor num curso on-line sem que ele tenha toda a oportunidade de preparar-se adequadamente para esse 


\begin{abstract}
E3, Revista de Economia, desafio. Os desgastes e as frustrações resultantes dessa imprudêncina fbłererã $\begin{gathered}\text { Empresas e Empreendedores } \\ \text { o }\end{gathered}$ docente e expô-lo desnecessariamente.
\end{abstract}

Devemos repensar também se esse docente necessita de uma qualificação subjetiva para exercer esse trabalho. Qualificações essas comuns todas as atividades, presentes no cotidiano contemporâneo desse profissional.

Fazendo uma análise desse ponto de vista, PRETI (2009, p.23-24) contribui para a discussão com o seguinte comentário: Mais do que aprender a fazer, ele deve ser formado para aprender a aprender. E isso, de maneira grupal, coletiva, com visão ampla, não fragmentada. A cooperação, a participação, a responsabilidade, a organização, a disciplina, a concentração e a assiduidade são atributos a ser assimilados e praticados por este novo tipo de profissional, um "novo" trabalhador, com boa formação geral, com capacidade para perceber um fenômeno em processo, mas atento, leal, responsável, capaz de tomar decisões. Fala-se, portanto, da necessidade de uma "reciclagem" dos trabalhadores. Isso vem consolidando a ideia de uma educação técnica e profissional permanente, continuada, de uma educação não restrita à escola e à educação formal.

Já não é mais possível pensar em educação ser que este se integre e interaja com os adventos tecnológicos, de comunicação e de tecnologia da informação. A educação também é virtual, pois pode ser acessada e estar disponível nas redes de comunicação e em bibliotecas virtuais na internet.

VIDAL (2010, p.21), traz mais uma contribuição disposta em sua obra, discorrendo sobre esses processos de transformações e mudanças no cenário educacional, que interferem diretamente os papéis do docente na Educação à Distância.

Todas essas mudanças no campo da informação, comunicação e conhecimento têm provocado desafios no plano da ação docente. As funções tradicionais dos professores têm sido questionadas em virtude da inclusão das tecnologias que chegam ao ambiente escolar. A sociedade do conhecimento do século XXI vem exigindo, cada vez mais, a melhoria dos padrões de qualidade na educação. Com isso demandam novas posturas profissionais daqueles que estão atuando em suas atividades laborais. A educação é convocada a revisarse, a instituir novas práticas e consolidar boas experiências e os professores são os principais atores mobilizados a apresentar respostas a esses processos de mudanças. Hoje, já não é possível ensinar do mesmo modo que se fazia no século passado. Os alunos não são os mesmos, dado que o conhecimento advindo das vivências sociais e cotidianas se ampliou, 


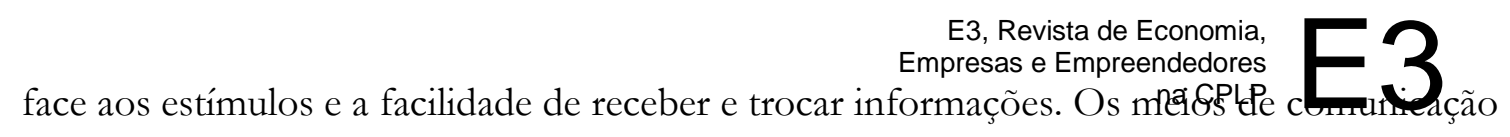
e as redes sociais alargaram o repertório de informações colaborando, juntamente com as instituições formais de ensino, para a formação pessoal e coletiva dos agentes no contexto da sociedade em que vivem e interagem.

Visando a adequação e as melhores práticas, utilizando dos princípios que a Educação à Distância tem de melhor, as instituições de sistema semi presencial e a distância, vem desenvolvendo novas formas de se pensar e de atuar, desenvolvendo estratégicas específicas que a diferencie e a torna particularmente contemporânea.

VIDAL (2010, p.22-23), contribui novamente explicando essa relação.

Cada experiência realizada, seja presencialmente ou a distância, tem suas especificidades e exige do docente uma adequação à sua proposta. O papel e a postura do docente passam, portanto, a ser influenciados não somente por seus atributos pessoais, mas também pelo projeto político pedagógico de cada programa, projeto ou ação educacional a que este se filia. Bons docentes na educação presencial não são necessariamente profissionais ideais para atuarem na $\mathrm{EAD}$, nem tampouco um bom professor no contexto da $\mathrm{EAD}$ tem equivalente performance na educação presencial, embora precisem ter atributos em comum. A diferença da linguagem oralizada adotada na modalidade presencial e da mediada pelos recursos midiáticos, a forma de interatividade, o design educacional, o cenário onde ocorrem as práticas pedagógicas, os mecanismos de estímulos visuais, sensoriais e cognitivos exigem estratégias pedagógicas que se adaptem as distintas realidades. Cabe ao professor de EAD desenvolver habilidades que permitam que os aprendentes passem a articular os saberes e as capacidades adquiridas para utilização na vida real.

O mais importante nessa relação é o de preparar esses docentes para o exercício das suas atribuições junto a Educação à Distância. Esses professores devem ser capacitados de forma a assimilar essa nova proposta pedagógica, com vínculos motivacionais e de estruturas tecnológicas e de sistemas de informação que atendam as suas necessidades enquanto docente e as necessidades, desejos e carências dos alunos. 


\section{Conclusão}

Muito provavelmente não podemos afirmar que exista uma "receita de bolo" com desenhos e ilustrações a respeito das práticas da docência em Educação à Distância. Podemos sim afirmar, que esses docentes deverão estar preparados para transformar através de uma nova ferramenta, um novo modelo, com novos conceitos, métodos e metodologias, porém levando sempre os alunos a atingirem os objetivos que foram traçados inicialmente e os auxiliando nessa encruzilhada educacional, onde os processos de ensino e aprendizagem, respaldados na disciplina e talvez até no auto conhecimento, tragam efetividade a essa formação, capacitação, graduação, aperfeiçoamento ou treinamento, inserido nesse contexto educacional recente, mas muito promissor.

PRETI (2009, p.25-26), discorre em sua obra sobre a abrangência e posição estratégica da Educação à Distância, suas diversidades e particularidades.

no contexto da crise estrutural do capitalismo, a conjuntura econômica, política e tecnológica tornou favorável a implementação da EAD. Ela passou a ocupar posição instrumental estratégica para satisfazer amplas e diversificadas necessidades de qualificação das pessoas adultas, para contenção de gastos nas áreas de serviços educacionais e, no âmbito ideológico, para traduzir a crença de que o conhecimento está disponível a quem quiser. Se antes existiam muitas resistências e pré-conceitos quanto à Educação a Distância, parece que a atual conjuntura encontrou nesta modalidade uma alternativa economicamente viável, uma opção às exigências sociais e pedagógicas, contando com o apoio do avanço das novas tecnologias da informação e da comunicação.

Devemos levar em conta também a questão imensurável do tempo. Buscam a EAD aqueles indivíduos que quer por necessidades pessoais e/ou profissionais, acabam por regrar o tempo disponível para a educação, seja ela qual for.

VIDAL (2010, p.20), complementa a discussão tratando dessa questão de forma ampla e abrangente.

O advento das tecnologias digitais (computador e internet) possibilitou uma ampliação ilimitada do acesso a informações e a velocidade de comunicação entre os mais diversos sujeitos. Tais ferramentas, quando utilizadas na educação a distância têm facilitado o acesso ao conhecimento a um maior número de pessoas, de forma virtual. As instituições educacionais públicas e privadas têm reagido as inovações advindas das tecnologias da informação e comunicação (TIC) e veem procurando se adaptar às atuais exigências do contexto social e tecnológico da era digital e dos benefícios por ela viabilizados. Para isso, elas têm constituído grupos de estudo e trabalho para reformulação dos cursos presenciais e 


\begin{abstract}
E3, Revista de Economia,

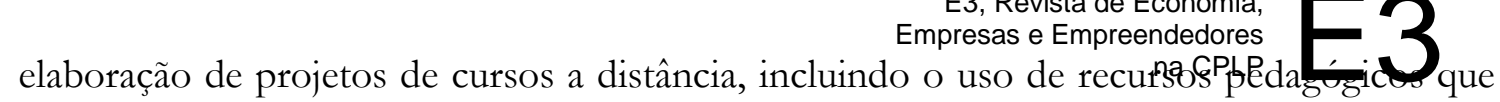
permitem a interatividade sincrônica (em tempo real) e assincrônica (em tempo diferido).
\end{abstract}

O fato de a Educação à Distância estar crescendo não há comprovação de que esse segmento de ensino irá superar a educação presencial, tida como convencional, até o momento. Pelas percepções do estudo em questão, respaldados pelos autores que contribuíram com essa discussão, podemos perceber uma tendência enorme de crescimento dessa modalidade de ensino e uma área próspera e faminta de profissionais qualificados, gabaritados e que atendam aos requisitos para o exercício dessa nova função dentro da educação.

As novas tecnologias irão direcionar essa modalidade da educação para que essas possam trazer facilidade e comodidade aos alunos e acadêmicos e outras responsabilidades, desafios, objetivos e metas aos docentes.

\title{
Referências
}

CANDAU. V.M. A didática e a formação de educadores - da exaltação à negociação: a busca da relevância. In CANDAU: V.M. (org.) A didática em questão. Petrópolis. Vozes. 1994.

CAPES. UAB - Universidade Aberta do Brasil. Disponível emhttp:/ / www.uab.capes.gov.br/index.php?option=com_content\&view=article\&id=6\&It emid=18. Acesso em 01/07/2014.

DINIZ, Ester. Educação a Distância: coletânea de textos para subsidiar a docência on-line. João Pessoa: Editora da UFPB, 2011.

ESTEVE, José M. A terceira revolução educacional: a educação na sociedade do conhecimento. São Paulo: Moderna, 2004.

GOMES, Silvane. Histórico da Ead no Brasil. Disponível em file:///G:/DIVERSOS/PPGDS/docencia $\% 20 \mathrm{do} \% 20$ ensino $\% 20$ superior/ARTIGOS $\% 20$ UTILIZADOS\%20PARA\%20O\%20MEU\%20ARTIGO/historia\%20ead\%203.pdffile:/ / /G:/DIVERSOS/PPGDS/docencia $\% 20 \mathrm{do} \% 20$ ensino\%20superior/ARTIGOS\%20UTIL 


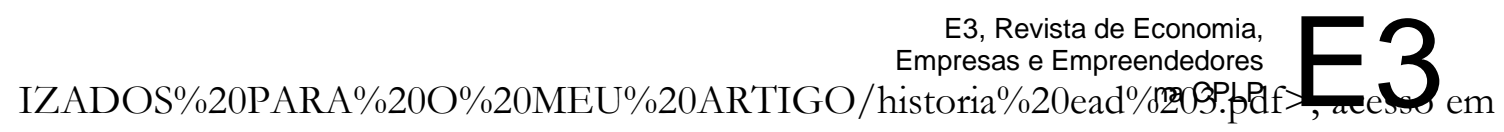
01.07.2014.

LEI $\mathrm{N}^{\circ}$ 9.394, de 20 de Dezembro DE 1996.Lei de diretrizes e bases da educaçãonacional.http://www.planalto.gov.br/ccivil_03/leis/19394.htm. Acesso em 01/07/2014

NOVA, Cristiane. Educação à distância: uma nova concepção de aprendizado e interatividade. São Paulo: Futura, 2003.

PRETI, Oreste. Educação a distância: fundamentos e políticas. Cuiabá: EdUFMT, 2009.

RASLAN, Valdinéia. Uma Comparação do Custo-Aluno entre o Ensino Superior Presencial e o Ensino Superior a Distância. Campo Grande, MS, 2009.

TARDIF. M. (2002). Saberes docentes e formação profissional. Petrópolis. Vozes. 2002.

TEPERINO, Adriana. Educação a distância em organizações públicas; mesa-redonda de pesquisa-ação. Brasília: ENAP, 2006.

VEIGA. I.P.A. As dimensões do processo didático na ação docente. In: ROMANOWSKI, J.P. et al. Conhecimento local e conhecimento universal: pesquisa, didática e ação docente. Curitiba. Champagnat. 2004

VIDAL, Eloísa. Introdução à Educação à Distância. Fortaleza: Editora RDS, 2010. 